\title{
Thermochemistry Is Not a Lower Bound to the Activation Energy of Endothermic Reactions: A Kinetic Study of the Gas-Phase Reaction of Atomic Chlorine with Ammonia ${ }^{\dagger}$
}

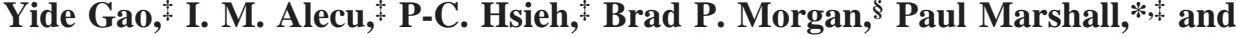 \\ Lev N. Krasnoperov" \\ Department of Chemistry, University of North Texas, P. O. Box 305070, Denton, Texas 76203-5070, \\ Department of Physical Sciences, Morehead State University, 123 Lappin Hall, Morehead, Kentucky 40351, \\ and Department of Chemistry and Environmental Science, New Jersey Institute of Technology, \\ Newark, New Jersey 07102
}

Received: November 6, 2005

\begin{abstract}
The rate constant for $\mathrm{Cl}+\mathrm{NH}_{3} \rightarrow \mathrm{HCl}+\mathrm{NH}_{2}$ has been measured over $290-570 \mathrm{~K}$ by the time-resolved resonance fluorescence technique. Ground-state $\mathrm{Cl}$ atoms were generated by $193 \mathrm{~nm}$ excimer laser photolysis of $\mathrm{CCl}_{4}$ and reacted under pseudo-first-order conditions with excess $\mathrm{NH}_{3}$. The forward rate constant was fit by the expression $k_{1}=(1.08 \pm 0.05) \times 10^{-11} \exp \left(-11.47 \pm 0.16 \mathrm{~kJ} \mathrm{~mol}^{-1} / \mathrm{RT}\right) \mathrm{cm}^{3} \mathrm{molecule}^{-1} \mathrm{~s}^{-1}$, where the uncertainties in the Arrhenius parameters are $\pm 1 \sigma$ and the $95 \%$ confidence limits for $k_{1}$ are $\pm 11 \%$. To rationalize the activation energy, which is $7.4 \mathrm{~kJ} \mathrm{~mol}^{-1}$ below the endothermicity in the middle of the $1 / T$ range, the potential energy surface was characterized with MPWB1K/6-31++G(2df,2p) theory. The products $\mathrm{NH}_{2}+\mathrm{HCl}$ form a hydrogen-bonded adduct, separated from $\mathrm{Cl}+\mathrm{NH}_{3}$ by a transition state lower in energy than the products. The rate constant for the reverse process $k_{-1}$ was derived via modified transition state theory, and the computed $k_{-1}$ exhibits a negative activation energy, which in combination with the experimental equilibrium constant yields $k_{1}$ in fair accord with experiment.
\end{abstract}

\section{Introduction}

A standard assumption is that, for an endothermic gas-phase reaction of the kind $\mathrm{A}+\mathrm{B} \rightarrow \mathrm{C}+\mathrm{D}$, a lower bound to the activation energy $E_{\mathrm{a}}$ for the rate constant $k$ is set by the overall enthalpy change $\Delta H^{\circ}{ }^{1,2}$ That is, $E_{\mathrm{a}}=-R \mathrm{~d}(\ln k) / \mathrm{d}(1 / T) \geq \Delta H^{\circ}$. However, the phenomenon of negative activation energies for apparently elementary gas-phase reactions is now wellknown. ${ }^{3-6}$ Some of these have been interpreted in terms of formation of an intermediate bound complex in the entrance channel, followed by a tight transition state (TS) whose energy lies below that of the reactants. ${ }^{7-9}$ Because the overall reaction enthalpy equals the difference between the activation energies for the forward and reverse reactions, ${ }^{10}$ a consequence is that the activation energy for the reverse of a process with a negative temperature dependence is less than its endothermicity. This may be important in cases where the observed $E_{\mathrm{a}}$ is used to set an upper limit to $\Delta H^{\circ}$, or in estimation of upper limits to rate constants where an assumed preexponential factor is combined with an $E_{\mathrm{a}}$ equal to $\Delta H^{\circ}$. There is little information in the literature concerning the validity of the assumption $E_{\mathrm{a}} \geq \Delta H^{\circ}$ for this kind of reaction where complexes might be involved in the exit channel. Here, we present the first determination of the temperature dependence of the rate constant $k_{1}$ for the endothermic reaction

$$
\mathrm{Cl}+\mathrm{NH}_{3} \rightarrow \mathrm{HCl}+\mathrm{NH}_{2}
$$

and compare it with the isoelectronic and also endothermic

\footnotetext{
$\dagger$ Part of the special issue "David M. Golden Festschrift".

* Corresponding author: marshall@unt.edu.

$\div$ University of North Texas.

$\S$ Morehead State University.

"New Jersey Institute of Technology.
}

reaction

$$
\mathrm{Cl}+\mathrm{CH}_{4} \rightarrow \mathrm{HCl}+\mathrm{CH}_{3}
$$

As will be seen, $E_{\mathrm{a}}$ is significantly below $\Delta H^{\circ}$ for reaction 1 , while $E_{\text {a }}$ exceeds $\Delta H^{\circ}$ for reaction 2. An important difference between the two reactions is that strong hydrogen bonding is only possible between the products of reaction 1 . This stabilizes the TS and leads to a negative $E_{\mathrm{a}}$ for the reverse of reaction 1 . A computational investigation of the potential energy surface (PES) confirms that the TS is followed by a hydrogen-bonded complex between $\mathrm{HCl}$ and $\mathrm{NH}_{2}$, and this PES is analyzed via transition-state theory for quantitative comparison with the measurements.

\section{Experimental Technique}

Details of the apparatus and its operation have been given previously. ${ }^{11,12}$ Briefly, ground-state atomic chlorine was produced by 193-nm excimer laser (MPB PSX-100, beam crosssection $7 \times 8 \mathrm{~mm}^{2}$ ) photolysis of $\mathrm{CCl}_{4}$ precursor and monitored by time-resolved resonance fluorescence at $134-140 \mathrm{~nm}\left((4 \mathrm{~s})^{2} \mathrm{P}\right.$ $\left.\rightarrow(4 \mathrm{p})^{2} \mathrm{P}_{1 / 2,3 / 2}\right){ }^{13}$ This fluorescence was excited by a microwave discharge through a separate flow of $\mathrm{Cl}_{2}(0.2 \%$ in $\mathrm{Ar}, 0.2 \mathrm{mbar}$ pressure). The experiments were conducted in a large excess of Ar bath gas to thermalize the system and to slow diffusion of $\mathrm{Cl}$ to the reactor walls. Low photolysis energies $F$ were employed, to minimize secondary chemistry involving photolysis or chemical products. Above $570 \mathrm{~K}$, so many $\mathrm{H}$ atoms were produced from $\mathrm{NH}_{3}$ photolysis that their fluorescence, excited by trace hydrogen impurities in the resonance lamp, interfered, despite the use of calcium fluoride optics. The initial atom concentration $[\mathrm{Cl}]_{0}$ was estimated from the laser fluence and the room-temperature absorption cross-section of $\mathrm{CCl}_{4} .{ }^{14}$ It does 


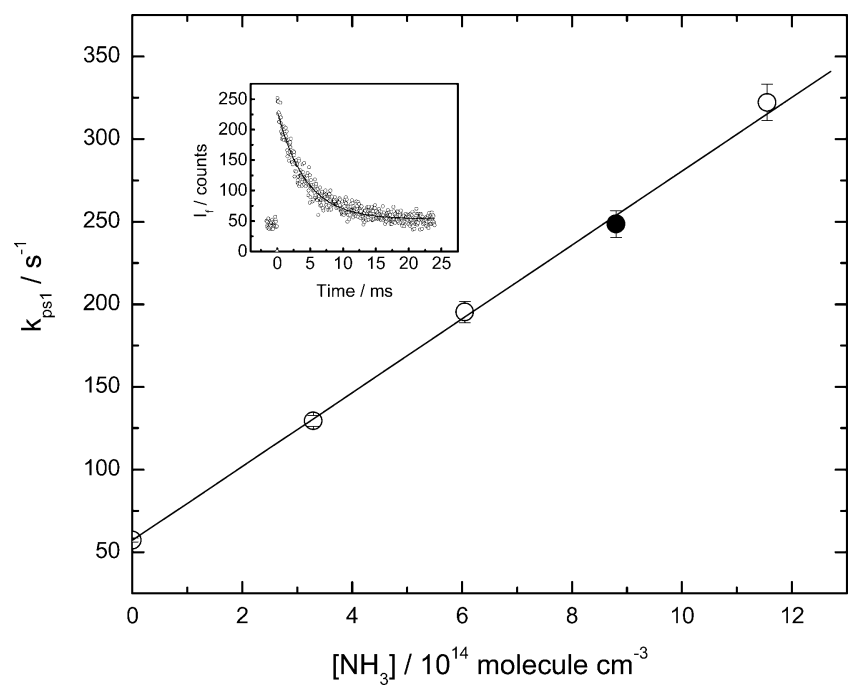

Figure 1. Plot of $k_{\mathrm{ps} 1}$ vs $\left[\mathrm{NH}_{3}\right]$ obtained at $357 \mathrm{~K}$. The error bars are $1 \sigma$. The inset shows the fluorescence signal plus background corresponding to the filled point.

not need to be known for the kinetic analysis, but verifies that the pseudo-first-order condition $[\mathrm{Cl}]_{0} \ll\left[\mathrm{NH}_{3}\right]$ was attained. The ammonia concentration is effectively constant, so that

$$
\mathrm{d}[\mathrm{Cl}] / \mathrm{d} t=-k_{1}\left[\mathrm{NH}_{3}\right][\mathrm{Cl}]-k^{\prime}[\mathrm{Cl}]=-k_{\mathrm{ps} 1}[\mathrm{Cl}]
$$

and exponential decays of the fluorescence signal were obtained. An example is shown in Figure 1. Nonlinear least-squares fitting provided the first-order decay coefficient $k_{\mathrm{ps} 1}$, and plots of $k_{\mathrm{ps} 1}$ vs $\left[\mathrm{NH}_{3}\right]$, such as that shown in Figure 1, have slopes equal to $k_{1}$. Typically, five values of $\left[\mathrm{NH}_{3}\right]$ were employed at each set of conditions, from zero to $\left[\mathrm{NH}_{3}\right]_{\max }$. The intercept $k^{\prime}$ arises from diffusional loss of $\mathrm{Cl}$ and any reaction with photolysis fragments of $\mathrm{CCl}_{4}$ and $\mathrm{NH}_{3}$. The experimental parameters pressure $p,[\mathrm{Cl}]_{0}, F$, and the residence time of gases in the heated reactor $\tau_{\text {res }}$ were varied to check for any influence on the measured $k_{1}$ values.

\section{Results and Discussion}

Eighty-three measurements over 290-570 K are summarized in Table 1. It may be seen that there is no systematic variation of $k_{1}$ with $p,[\mathrm{Cl}]_{0}, F$, and $\tau_{\text {res, }}$, which indicates that the reaction is effectively bimolecular, has been successfully isolated from any secondary chemistry, and is unaffected by decomposition of the reactants inside the heated reaction cell. Potential interference might arise from condensation of $\mathrm{HCl}$ product with $\mathrm{NH}_{3}$ to form solid $\mathrm{NH}_{4} \mathrm{Cl}$, but no obvious light scattering problems were encountered. The kinetic data are plotted in Arrhenius form in Figure 2. A weighted linear fit was based on the $1 \sigma$ uncertainties in the slopes of plots such as Figure 1, listed in Table 1 , combined with an estimated $\sigma_{\mathrm{T}} / T=2 \%$, and yielded

$k_{1}=(1.08 \pm 0.05) \times$

$10^{-11} \exp \left(-11.47 \pm 0.16 \mathrm{~kJ} \mathrm{~mol}^{-1} / R T\right) \mathrm{cm}^{3}$ molecule $\mathrm{s}^{-1}$

where the uncertainties in the Arrhenius parameters are $\pm 1 \sigma$. Together with the covariance and a $10 \%$ allowance for potential systematic errors, these yield $95 \%$ confidence limits of $\pm 11 \%$ for $k_{1}$. The only prior measurement of reaction 1 was made by Westenberg and DeHaas with flash lamp photolysis of the same $\mathrm{CCl}_{4}$ precursor, and they obtained $(1.23 \pm 0.02) \times 10^{-13} \mathrm{~cm}^{3}$

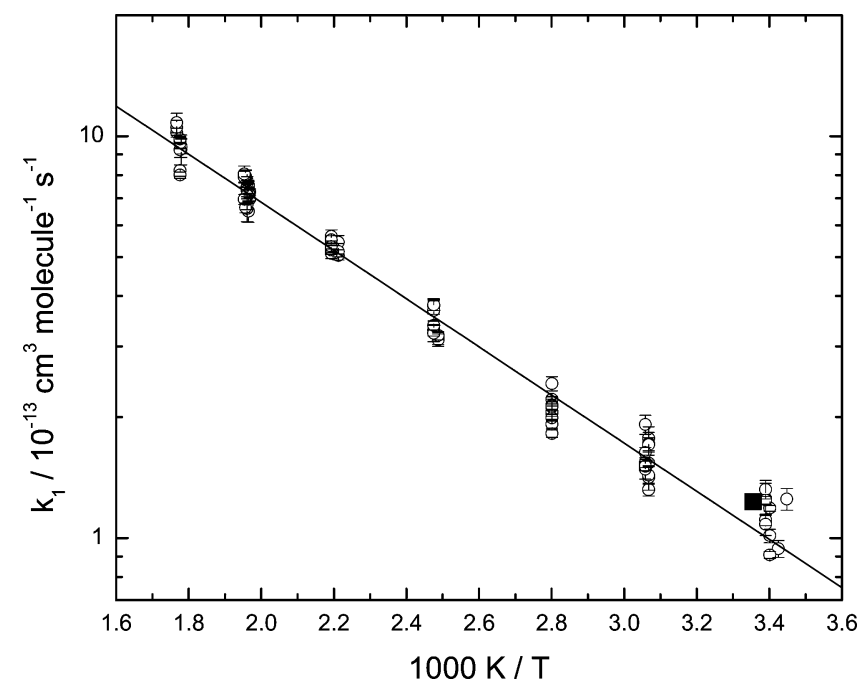

Figure 2. Arrhenius plot for $\mathrm{Cl}+\mathrm{NH}_{3}$. Open circles, present measurements with $1 \sigma$ statistical error bars; solid square, measurement by Westenberg and deHaas. ${ }^{15}$

molecule ${ }^{-1} \mathrm{~s}^{-1}$ at room temperature. ${ }^{15}$ As may be seen from Figure 2, this earlier result lies in the range of our measurements.

Figure 2 also shows that most of the measurements at room temperature lie slightly above the linear Arrhenius fit. This could indicate slight curvature in the Arrhenius plot or that a second channel becomes important at low temperatures. A possible adduct is discussed in the next section. However, we note that there is no systematic pressure influence on the room-temperature data, over a variation of more than a factor of 5 . This is evidence against an addition pathway, which would be expected to be pressure-dependent. If such a path was at its high-pressure limit under our conditions, then rate constants of around $10^{-10}$ $\mathrm{cm}^{3}$ molecule ${ }^{-1} \mathrm{~s}^{-1}$ would be expected. Most likely, the adduct is thermodynamically unstable, as discussed in the following section.

The thermochemistry of reaction 1 is well-established. The spectroscopic measurements of Mordaunt et al. yield a precise bond strength for ammonia of $444.0 \pm 0.2 \mathrm{~kJ} \mathrm{~mol}^{-1}$ at $0 \mathrm{~K},{ }^{16}$ and the bond strength of $\mathrm{HCl}$ from Gurvich et al. is $427.8 \pm$ $0.1 \mathrm{~kJ} \mathrm{~mol}^{-1}{ }^{17}$ The difference is $\Delta H_{0}^{\circ}=16.2 \pm 0.2 \mathrm{~kJ} \mathrm{~mol}^{-1}$, and via tabulated temperature dependences of the enthalpies, ${ }^{17}$ at the approximate center of the $T^{-1}$ range, $\Delta H_{400}^{\circ}=18.9 \mathrm{~kJ}$ $\mathrm{mol}^{-1}$, significantly larger than the measured activation energy. Because, as noted in the Introduction, $\Delta H^{\circ}=E_{\mathrm{a}}\left(k_{1}\right)-E_{\mathrm{a}}\left(k_{-1}\right),{ }^{10}$ the activation energy of the reverse process must be negative.

Reaction 1 can be compared with the isoelectronic reaction 2 . The measured variation of $k_{2}$ with temperature yields a curved Arrhenius plot, ${ }^{18}$ and near the middle of the same temperature range as here yields average Arrhenius parameters of about $A$ $=1.9 \times 10^{-11} \mathrm{~cm}^{3}$ molecule $\mathrm{s}^{-1} \mathrm{~s}^{-1}$ and $E_{\mathrm{a}}=13.1 \mathrm{~kJ} \mathrm{~mol}^{-1}$. These parameters and the corresponding $k_{2}$ values are similar to those determined here. The activation energy for reaction 2 is slightly larger than for 1 , but by contrast to the latter case, it exceeds the endothermicity, where for reaction $2, \Delta H_{298}^{\circ}=7.5$ $\pm 0.3 \mathrm{~kJ} \mathrm{~mol}^{-1}$ and $\Delta H_{400}^{\circ}=8.4 \pm 0.3 \mathrm{~kJ} \mathrm{~mol}^{-1} \cdot{ }^{17,19,20}$ Quantitative analysis of reaction 2 includes no role for bound intermediates, ${ }^{21}$ and we would expect no strong interaction between $\mathrm{CH}_{3}$ and $\mathrm{HCl}$. Their reaction, the reverse of reaction 2 , has a positive temperature dependence. ${ }^{22}$ The electronegativity of nitrogen makes hydrogen bonding feasible between $\mathrm{NH}_{2}$ and $\mathrm{HCl}$, which, apart from leading to a bound intermediate, also stabilizes the transition state for the reaction. This idea, and 
6846 J. Phys. Chem. A, Vol. 110, No. 21, 2006

Gao et al.

TABLE 1: Summary of Measurements of the Rate Constant $k_{1}$ for $\mathrm{Cl}+\mathrm{NH}_{3}$

\begin{tabular}{|c|c|c|c|c|c|c|c|}
\hline$T \mathrm{~K}$ & $\begin{array}{c}\tau_{\text {res }} \\
\mathrm{s}\end{array}$ & $\begin{array}{c}F \\
\mathrm{~mJ}\end{array}$ & $\begin{array}{c}p \\
\text { mbar }\end{array}$ & $\begin{array}{c}{\left[\mathrm{CCl}_{4}\right]} \\
10^{15} \text { molecule } \mathrm{cm}^{-3}\end{array}$ & $\begin{array}{c}{\left[\mathrm{NH}_{3}\right]_{\max }} \\
10^{15}{\text { molecule } \mathrm{cm}^{-3}}^{-3}\end{array}$ & $\begin{array}{c}{[\mathrm{Cl}]_{0}} \\
10^{12} \text { molecule } \mathrm{cm}^{-3}\end{array}$ & $\begin{array}{c}k_{1} \pm \sigma_{\mathrm{k} 1} \\
10^{-13} \mathrm{~cm}^{3} \text { molecule }^{-1} \mathrm{~s}^{-1}\end{array}$ \\
\hline 290 & 1.2 & 0.41 & 28 & 2.72 & 3.47 & 0.9 & $1.25 \pm 0.08$ \\
\hline 292 & 0.9 & 0.18 & 43 & 1.80 & 1.51 & 0.3 & $0.94 \pm 0.05$ \\
\hline 294 & 2.2 & 0.21 & 49 & 4.05 & 1.27 & 0.7 & $0.91 \pm 0.02$ \\
\hline 294 & 6.9 & 0.20 & 147 & 5.54 & 2.05 & 0.9 & $1.19 \pm 0.02$ \\
\hline 294 & 1.6 & 0.11 & 36 & 3.77 & 1.48 & 0.3 & $1.01 \pm 0.04$ \\
\hline 295 & 4.9 & 0.15 & 155 & 5.45 & 3.09 & 0.7 & $1.25 \pm 0.12$ \\
\hline 295 & 3.6 & 0.30 & 80 & 5.93 & 2.19 & 1.5 & $1.32 \pm 0.07$ \\
\hline 295 & 3.6 & 0.19 & 80 & 5.93 & 2.19 & 0.9 & $1.11 \pm 0.04$ \\
\hline 295 & 3.4 & 0.14 & 76 & 5.64 & 1.42 & 0.6 & $1.24 \pm 0.03$ \\
\hline 295 & 3.5 & 0.09 & 79 & 5.94 & 1.24 & 0.4 & $1.08 \pm 0.07$ \\
\hline 326 & 1.4 & 0.79 & 35 & 2.09 & 1.31 & 1.4 & $1.77 \pm 0.12$ \\
\hline 326 & 1.4 & 0.59 & 35 & 2.09 & 1.31 & 1.0 & $1.72 \pm 0.11$ \\
\hline 326 & 1.4 & 0.36 & 35 & 2.09 & 1.31 & 0.6 & $1.41 \pm 0.10$ \\
\hline 326 & 1.4 & 0.25 & 35 & 2.09 & 1.31 & 0.4 & $1.32 \pm 0.05$ \\
\hline 326 & 1.6 & 0.59 & 71 & 2.32 & 1.46 & 1.1 & $1.71 \pm 0.07$ \\
\hline 326 & 1.6 & 0.35 & 71 & 2.32 & 1.46 & 0.7 & $1.54 \pm 0.03$ \\
\hline 326 & 1.6 & 0.25 & 71 & 2.32 & 1.46 & 0.5 & $1.43 \pm 0.07$ \\
\hline 327 & 3.0 & 0.49 & 73 & 2.90 & 1.56 & 1.2 & $1.92 \pm 0.10$ \\
\hline 327 & 3.0 & 0.29 & 73 & 2.90 & 1.56 & 0.7 & $1.63 \pm 0.05$ \\
\hline 327 & 3.0 & 0.19 & 73 & 2.90 & 1.56 & 0.5 & $1.48 \pm 0.08$ \\
\hline 327 & 2.3 & 0.29 & 148 & 2.75 & 1.16 & 0.7 & $1.54 \pm 0.04$ \\
\hline 327 & 2.3 & 0.19 & 148 & 2.75 & 1.16 & 0.4 & $1.51 \pm 0.04$ \\
\hline 357 & 2.7 & 0.49 & 72 & 2.59 & 1.13 & 1.1 & $2.04 \pm 0.09$ \\
\hline 357 & 2.7 & 0.29 & 72 & 2.59 & 1.13 & 0.6 & $1.82 \pm 0.04$ \\
\hline 357 & 2.7 & 0.19 & 72 & 2.59 & 1.13 & 0.4 & $1.92 \pm 0.04$ \\
\hline 357 & 1.4 & 0.69 & 72 & 2.91 & 1.16 & 1.7 & $2.42 \pm 0.10$ \\
\hline 357 & 1.4 & 0.44 & 72 & 2.91 & 1.16 & 1.1 & $2.21 \pm 0.03$ \\
\hline 357 & 1.4 & 0.29 & 72 & 2.91 & 1.16 & 0.7 & $2.06 \pm 0.03$ \\
\hline 357 & 2.1 & 0.44 & 148 & 2.51 & 1.25 & 0.9 & $2.12 \pm 0.04$ \\
\hline 357 & 2.1 & 0.29 & 148 & 2.51 & 1.25 & 0.6 & $1.99 \pm 0.02$ \\
\hline 357 & 1.3 & 0.69 & 36 & 2.34 & 1.13 & 1.3 & $2.15 \pm 0.11$ \\
\hline 357 & 1.3 & 0.44 & 36 & 2.34 & 1.13 & 0.9 & $2.14 \pm 0.10$ \\
\hline 357 & 1.3 & 0.29 & 36 & 2.34 & 1.13 & 0.6 & $2.13 \pm 0.09$ \\
\hline 402 & 0.7 & 0.62 & 59 & 1.69 & 1.73 & 0.9 & $3.14 \pm 0.11$ \\
\hline 402 & 0.7 & 0.39 & 59 & 1.69 & 1.73 & 0.6 & $3.11 \pm 0.11$ \\
\hline 402 & 0.7 & 0.19 & 59 & 1.69 & 1.73 & 0.3 & $3.19 \pm 0.08$ \\
\hline 404 & 1.3 & 0.65 & 61 & 2.01 & 1.18 & 1.1 & $3.77 \pm 0.17$ \\
\hline 404 & 1.3 & 0.50 & 61 & 2.01 & 1.18 & 0.8 & $3.68 \pm 0.21$ \\
\hline 404 & 1.3 & 0.20 & 61 & 2.01 & 1.18 & 0.3 & $3.80 \pm 0.12$ \\
\hline 404 & 0.6 & 0.60 & 29 & 1.53 & 1.57 & 0.8 & $3.29 \pm 0.11$ \\
\hline 404 & 0.6 & 0.42 & 29 & 1.53 & 1.57 & 0.5 & $3.23 \pm 0.15$ \\
\hline 404 & 0.6 & 0.18 & 29 & 1.53 & 1.57 & 0.2 & $3.38 \pm 0.09$ \\
\hline 452 & 0.6 & 0.79 & 59 & 1.46 & 1.22 & 1.0 & $5.05 \pm 0.04$ \\
\hline 452 & 0.6 & 0.58 & 59 & 1.46 & 1.22 & 0.7 & $5.44 \pm 0.22$ \\
\hline 452 & 0.6 & 0.24 & 59 & 1.46 & 1.22 & 0.3 & $5.16 \pm 0.24$ \\
\hline 456 & 0.5 & 0.63 & 29 & 1.61 & 1.13 & 0.8 & $5.41 \pm 0.24$ \\
\hline 456 & 0.5 & 0.45 & 29 & 1.61 & 1.13 & 0.6 & $5.63 \pm 0.21$ \\
\hline 456 & 0.5 & 0.28 & 29 & 1.61 & 1.13 & 0.4 & $5.52 \pm 0.13$ \\
\hline 456 & 1.1 & 0.73 & 57 & 1.65 & 1.21 & 1.0 & $5.10 \pm 0.14$ \\
\hline 456 & 1.1 & 0.54 & 57 & 1.65 & 1.21 & 0.7 & $5.21 \pm 0.13$ \\
\hline 456 & 1.1 & 0.26 & 57 & 1.65 & 1.21 & 0.4 & $5.31 \pm 0.18$ \\
\hline 508 & 0.5 & 0.34 & 57 & 1.27 & 1.50 & 0.4 & $6.97 \pm 0.06$ \\
\hline 508 & 0.5 & 0.23 & 57 & 1.27 & 1.50 & 0.2 & $7.26 \pm 0.13$ \\
\hline 509 & 0.9 & 0.69 & 71 & 1.76 & 1.29 & 1.0 & $6.50 \pm 0.40$ \\
\hline 509 & 0.9 & 0.37 & 71 & 1.76 & 1.29 & 0.5 & $7.24 \pm 0.38$ \\
\hline 509 & 0.9 & 0.24 & 71 & 1.76 & 1.29 & 0.4 & $7.46 \pm 0.26$ \\
\hline 509 & 0.9 & 0.18 & 71 & 1.76 & 1.29 & 0.3 & $7.54 \pm 0.21$ \\
\hline 510 & 0.3 & 0.43 & 22 & 0.98 & 1.86 & 0.4 & $6.60 \pm 0.47$ \\
\hline 510 & 0.3 & 0.20 & 22 & 0.98 & 1.86 & 0.2 & $7.09 \pm 0.52$ \\
\hline 510 & 0.6 & 0.36 & 45 & 1.38 & 1.95 & 0.4 & $6.74 \pm 0.62$ \\
\hline 510 & 0.6 & 0.17 & 45 & 1.38 & 1.95 & 0.2 & $7.47 \pm 0.28$ \\
\hline 510 & 0.6 & 0.83 & 44 & 1.32 & 1.69 & 0.9 & $7.33 \pm 0.35$ \\
\hline 510 & 0.6 & 0.34 & 44 & 1.32 & 1.69 & 0.4 & $7.13 \pm 0.32$ \\
\hline 510 & 0.6 & 0.16 & 44 & 1.32 & 1.69 & 0.2 & $7.75 \pm 0.18$ \\
\hline 511 & 0.5 & 0.64 & 30 & 1.22 & 1.45 & 0.7 & $6.64 \pm 0.19$ \\
\hline 511 & 0.5 & 0.51 & 30 & 1.22 & 1.45 & 0.5 & $6.98 \pm 0.20$ \\
\hline 511 & 0.5 & 0.28 & 30 & 1.22 & 1.45 & 0.3 & $7.85 \pm 0.39$ \\
\hline 511 & 0.8 & 0.41 & 63 & 2.02 & 1.31 & 0.7 & $7.94 \pm 0.27$ \\
\hline 512 & 1.0 & 0.59 & 59 & 1.54 & 2.12 & 0.8 & $6.96 \pm 0.20$ \\
\hline 512 & 1.0 & 0.25 & 59 & 1.54 & 2.12 & 0.3 & $7.91 \pm 0.26$ \\
\hline 512 & 1.0 & 0.17 & 59 & 1.54 & 2.12 & 0.2 & $8.05 \pm 0.37$ \\
\hline 562 & 0.5 & 0.67 & 45 & 1.42 & 1.73 & 0.8 & $9.28 \pm 0.79$ \\
\hline
\end{tabular}


TABLE 1 (Continued)

\begin{tabular}{|c|c|c|c|c|c|c|c|}
\hline$T \mathrm{~K}$ & $\begin{array}{c}\tau_{\text {res }} \\
\mathrm{s}\end{array}$ & $\begin{array}{c}F \\
\mathrm{~mJ}\end{array}$ & $\begin{array}{c}p \\
\text { mbar }\end{array}$ & $\begin{array}{c}{\left[\mathrm{CCl}_{4}\right]} \\
10^{15} \text { molecule } \mathrm{cm}^{-3}\end{array}$ & $\begin{array}{c}{\left[\mathrm{NH}_{3}\right]_{\max }} \\
10^{15} \text { molecule } \mathrm{cm}^{-3}\end{array}$ & $\begin{array}{c}{[\mathrm{Cl}]_{0}} \\
10^{12} \text { molecule } \mathrm{cm}^{-3}\end{array}$ & $\begin{array}{c}k_{1} \pm \sigma_{\mathrm{k} 1} \\
10^{-13} \mathrm{~cm}^{3} \text { molecule }{ }^{-1} \mathrm{~s}^{-1}\end{array}$ \\
\hline 562 & 0.5 & 0.44 & 45 & 1.42 & 1.73 & 0.5 & $9.36 \pm 0.51$ \\
\hline 562 & 0.5 & 0.22 & 45 & 1.42 & 1.73 & 0.3 & $9.43 \pm 0.40$ \\
\hline 563 & 0.5 & 0.59 & 22 & 1.35 & 1.47 & 0.7 & $8.21 \pm 0.27$ \\
\hline 563 & 0.5 & 0.37 & 22 & 1.35 & 1.47 & 0.4 & $9.24 \pm 0.40$ \\
\hline 563 & 0.5 & 0.27 & 22 & 1.35 & 1.47 & 0.3 & $9.66 \pm 0.32$ \\
\hline 563 & 0.9 & 0.76 & 44 & 1.84 & 1.48 & 1.2 & $8.00 \pm 0.14$ \\
\hline 563 & 0.9 & 0.38 & 44 & 1.84 & 1.48 & 0.6 & $9.61 \pm 0.31$ \\
\hline 563 & 0.9 & 0.24 & 44 & 1.84 & 1.48 & 0.4 & $9.83 \pm 0.24$ \\
\hline 566 & 0.5 & 0.61 & 43 & 1.85 & 1.06 & 0.9 & $10.20 \pm 0.27$ \\
\hline 566 & 0.5 & 0.39 & 43 & 1.85 & 1.06 & 0.6 & $10.50 \pm 0.45$ \\
\hline 566 & 0.5 & 0.19 & 43 & 1.85 & 1.06 & 0.3 & $10.80 \pm 0.61$ \\
\hline
\end{tabular}

TABLE 2: Enthalpies at $0 \mathrm{~K}$ of Stationary Points on the Potential Energy Surface Relative to Cl $+\mathrm{NH}_{3}$, Derived by Various Methods

\begin{tabular}{|c|c|c|c|c|}
\hline method & $\mathrm{NH}_{2}+\mathrm{HCl}$ & $\begin{array}{c}\mathrm{Cl}-\mathrm{NH}_{3} \\
\text { 2c-3e adduct }\end{array}$ & $\begin{array}{l}\text { transition } \\
\text { state }\end{array}$ & $\begin{array}{c}\mathrm{H}_{2} \mathrm{~N}-\mathrm{HCl} \\
\text { intermediate }\end{array}$ \\
\hline CBS-QB3 & 15.1 & -40.3 & 9.4 & -1.7 \\
\hline G3B3 & 14.0 & -36.6 & 11.2 & -1.9 \\
\hline MPWB1K/6-31+G(d,p) & 26.2 & -52.5 & 12.8 & 1.5 \\
\hline MPWB1K/6-31+G(2d,p) & 19.0 & -50.2 & 9.8 & -0.3 \\
\hline $\mathrm{MPWB} 1 \mathrm{~K} / 6-31++\mathrm{G}(2 \mathrm{~d}, 2 \mathrm{p})$ & 17.5 & -49.1 & 8.1 & -1.6 \\
\hline MPWB $1 \mathrm{~K} / 6-31+\mathrm{G}(2 \mathrm{df}, 2 \mathrm{p})$ & 17.2 & -47.7 & 9.0 & -1.3 \\
\hline MPWB $1 \mathrm{~K} / 6-31++\mathrm{G}(2 \mathrm{df}, 2 \mathrm{p})$ & 17.0 & -47.7 & 8.8 & -1.4 \\
\hline MPWB1K/6-311+G(d,p) & 20.9 & -51.3 & 9.0 & -2.2 \\
\hline MPWB1K/6-311++G(2df,2p) & 15.1 & -48.3 & 7.3 & -1.9 \\
\hline MPWB1K/6-311++G(3d2f,2df,2p) & 14.6 & -47.2 & 8.4 & -2.5 \\
\hline experiment & $16.2 \pm 0.1$ & & & \\
\hline
\end{tabular}

the prediction of a negative activation energy for $k_{-1}$, is explored quantitatively in the next section.

\section{Theoretical Analysis}

The Gaussian 03 program suite ${ }^{23}$ was employed to calculate geometries, vibrational frequencies, and energies of stationary points on the PES. Several approaches were used. The composite G3B3 and CBS-QB3 ab initio methodologies were applied ${ }^{24,25}$ and also the MPWB1K density functional developed by Zhao and Truhlar for systems involving hydrogen bonding and reaction barriers. ${ }^{26}$ These DFT calculations were applied with a variety of basis sets, and the vibrational frequencies were scaled by a factor of $0.955 .{ }^{26} \mathrm{G} 3$ theory includes a spin-orbit correction of $-3.5 \mathrm{~kJ} \mathrm{~mol}^{-1}$ to the energy of atomic $\mathrm{Cl}$, and this correction was applied to the other levels of theory. Spin contamination was negligible, with $\left\langle S^{2}\right\rangle$ spin expectation values for the open-shell species of at most 0.757 , cf. the ideal value of exactly 0.75 . Table 2 summarizes the results.

The two composite ab initio approaches are in good accord with the overall reaction enthalpy, although they underestimate $\Delta H_{0}^{\circ}$ by up to $2 \mathrm{~kJ} \mathrm{~mol}^{-1}$ (which is within their target accuracies). The DFT results show systematic variation with the size of the basis set, with errors ranging from $+10 \mathrm{~kJ} \mathrm{~mol}^{-1}$ with the smallest $6-31+\mathrm{G}(\mathrm{d}, \mathrm{p})$ basis set considered to $-2 \mathrm{~kJ}$ $\mathrm{mol}^{-1}$ with the largest $6-311++\mathrm{G}(3 \mathrm{~d} 2 \mathrm{f}, 2 \mathrm{df}, 2 \mathrm{p})$ basis set. These two basis sets were denoted DIDZ and MG3 by Zhao and Truhlar. ${ }^{26}$ The trend suggests that an intermediate-sized basis set may give close accord with the experimental $\Delta H_{0}^{\circ}$, and accordingly, we focus on MPWB1K/6-31++G(2df,2p) results which give the best agreement with $\Delta H_{0}^{\circ}$. Corresponding geometries of stationary points are shown in Figure 3.

A molecule with a long $\left(\sim 2.4 \times 10^{-10} \mathrm{~m}\right)$ two-center/threeelectron $\mathrm{Cl}-\mathrm{N}$ bond has been characterized previously, and our calculations are in general accord with those of McKee et al. ${ }^{27}$ MPWB1K/6-31++G(2df,2p) geometries and frequencies imply that the equilibrium constant $K_{\mathrm{c}}$ for $\mathrm{Cl}-\mathrm{NH}_{3}$ formation at 290
$\mathrm{K}$ is $1.2 \times 10^{-24} \exp (\mathrm{BDE} / R T) \mathrm{cm}^{3}$ molecule ${ }^{-1}$, where $\mathrm{BDE}$ is the $0 \mathrm{~K}$ bond dissociation enthalpy. With a DFT value of $48 \mathrm{~kJ}$ $\mathrm{mol}^{-1}, K_{\mathrm{c}} \approx 5 \times 10^{-16} \mathrm{~cm}^{3}$ molecule ${ }^{-1}$, which implies that under the most favorable conditions (maximum $\left[\mathrm{NH}_{3}\right]$ and lowest $T$ ) up to two-thirds of the initial atomic $\mathrm{Cl}$ could be complexed by $\mathrm{NH}_{3}$. Most of the room temperature runs would have a smaller fraction of $\mathrm{Cl}$ potentially complexed. The lack of observed $p$-dependence suggests that the two-center/threeelectron species is not significantly formed in our experiments. The implication is that the BDE is probably slightly smaller than $48 \mathrm{~kJ} \mathrm{~mol}^{-1}$ and more in line with the ab initio values listed in Table 2. Lower-temperature experiments would check this proposition.

The potential energy diagram shown in Figure 4 reveals a TS with an energy below that of the final products, with an intervening complex bound by about $18 \mathrm{~kJ} \mathrm{~mol}^{-1}$ relative to $\mathrm{NH}_{2}+\mathrm{HCl}$. The structure and energy of this complex are consistent with hydrogen bonding, and no barrier was found for dissociation to $\mathrm{NH}_{2}+\mathrm{HCl}$. Energy optimizations starting with other $\mathrm{Cl}-\mathrm{H}-\mathrm{N}$ arrangements did not lead to new bound species. We now analyze this PES to derive rate constants for comparison with experiment, through consideration of the reverse process

$$
\mathrm{NH}_{2}+\mathrm{HCl} \rightarrow \mathrm{Cl}+\mathrm{NH}_{3}
$$

and then derive $k_{1}$ via microscopic reversibility: $k_{1} / k_{-1}=K_{\text {eq }}$ where the equilibrium constant was obtained from tabulated data $^{17}$ and the $\Delta H_{0}^{\circ}$ derived above. This yields, to within $6 \%$, $K_{\text {eq }}=27.3 T^{-0.049} \exp (-2248 / T)$ over $200-2000 \mathrm{~K}$.

$k_{-1}$ is derived via modified transition state theory (MTST). The standard TST result for the microcanonical rate constant is $k(E)=W^{\ddagger}\left(E^{+}\right) / h \rho_{\mathrm{R}}(E),{ }^{28}$ where $\rho_{\mathrm{R}}(E)$ is the density of states of the reactants at energy $E, W^{\ddagger}\left(E^{+}\right)$is the total number of states of the TS with an energy below $E^{+}=E-E_{0}$, counting from the ground state of the TS, and $E_{0}$ is the barrier height relative to the reactants. In the case where this 


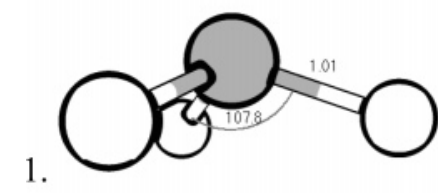

4.

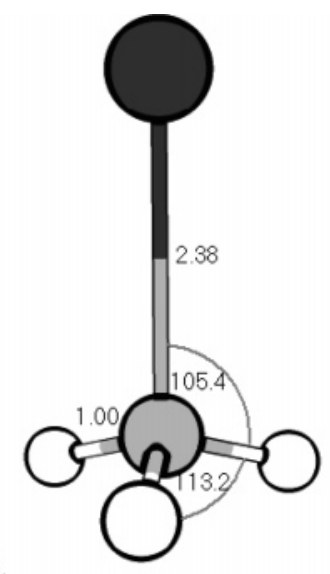

2 .

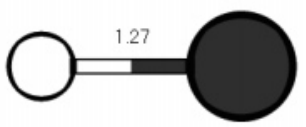

3.

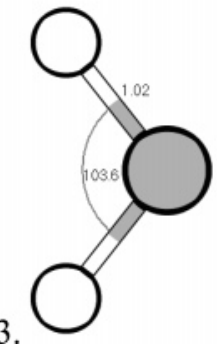

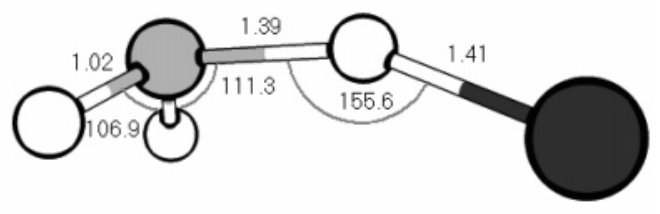

6.

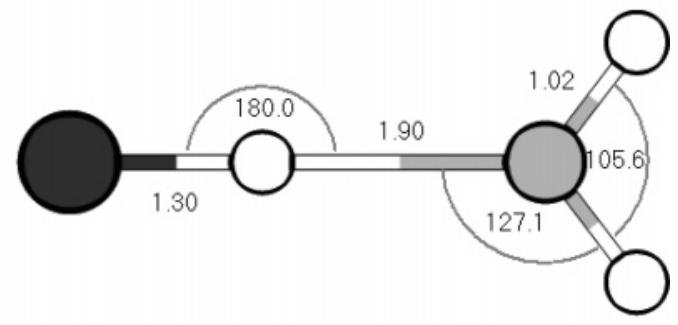

Figure 3. Geometries and frequencies (scaled by 0.955 ) of stationary points on the $\mathrm{Cl}+\mathrm{NH}_{3}$ potential energy surface, computed via MPWB1K/ 6-31++G(2df,2p) theory: $1 . C_{3 v} \mathrm{NH}_{3}, 977,1610(2), 3440,3576(2) \mathrm{cm}^{-1} .2 . \mathrm{HCl}, 2932 \mathrm{~cm}^{-1} .3 . C_{2 v} \mathrm{NH}_{2}, 1475,3332,3427 \mathrm{~cm}^{-1} .4 . C_{3 v} \mathrm{Cl}-\mathrm{NH}{ }_{3}$ adduct, 297, 342 (2), 817, $1570(2), 3466,3614(2) \mathrm{cm}^{-1}$. 5. $C_{s}$ transition state, 622i, 391, 400, 677, 984, 1180, 1502, 3376, 3481 $\mathrm{cm}^{-1} .6 . C_{2 v}$ $\mathrm{H}_{2} \mathrm{~N}-\mathrm{HCl}$ complex, $153,156,185,556,577,1472,2568,3358,3461 \mathrm{~cm}^{-1}$.

barrier is positive, $k\left(E^{+}<0\right)=0$, and thus

$$
\begin{aligned}
k(T) & =\frac{1}{Q_{\mathrm{R}}} \int_{E_{0}}^{\infty} \exp (-E / k T) \rho_{\mathrm{R}}(E) k\left(E^{+}\right) \mathrm{d} E \\
& =\frac{k T}{h} \frac{\exp \left(-E_{0} / k T\right)}{Q_{\mathrm{R}}} \int_{0}^{\infty} \rho^{\ddagger}\left(E^{+}\right) \exp \left(-E^{+} / k T\right) \mathrm{d} E^{+} \\
& =\frac{k T}{h} \frac{Q^{\ddagger}}{Q_{\mathrm{R}}} \exp \left(-E_{0} / k T\right)
\end{aligned}
$$

where $Q^{\ddagger}$ and $Q_{\mathrm{R}}$ are the partition functions for the TS and reactants, respectively. This is the usual TST result for $k(T)$.

For a reaction such as -1 , where $E_{0}<0$, eq 5 is not applicable. At normal pressures, collisions are not rapid enough to thermalize the energy levels of the TS, and therefore, energy levels below the reactants are inaccessible (except in solution or at very high gas density). Thus, $E \geq 0$, and the lower bound of the first integration of eq 4 must be zero, which leads to

$$
\begin{aligned}
k(T) & =\frac{1}{Q_{\mathrm{R}}} \int_{0}^{\infty} \exp (-E / k T) \rho_{\mathrm{R}}(E) k\left(E^{+}\right) \mathrm{d} E \\
& =\frac{k T \exp \left(-E_{0} / k T\right)}{h Q_{\mathrm{R}}} \int_{-E_{0}}^{\infty} W^{\ddagger}\left(E^{+}\right) \exp \left(-E^{+} / k T\right) \frac{\mathrm{d} E^{+}}{k T}
\end{aligned}
$$

This result was noted by Garrett et al. in the context of improved canonical variational $\mathrm{TST}^{29}$ and has recently been explored

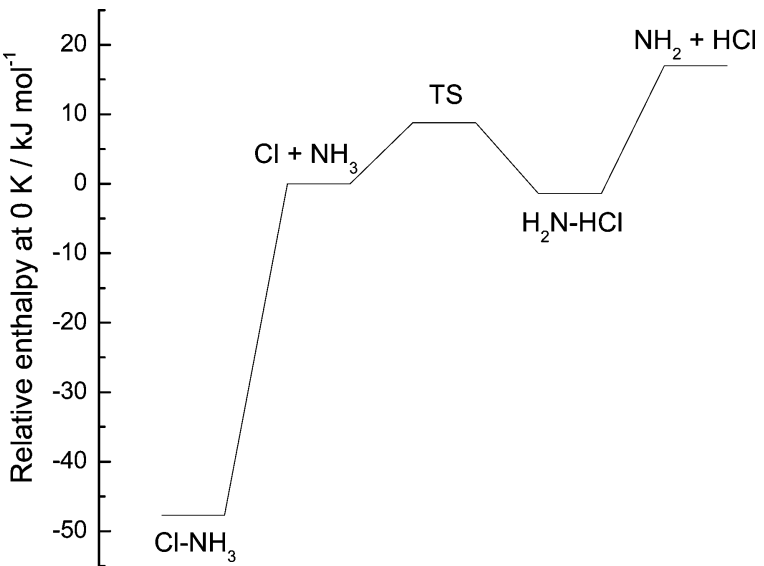

Figure 4. Potential energy diagram for $\mathrm{Cl}+\mathrm{NH}_{3}$ computed at the MPWB1K/6-31++G(2df,2p) level of theory.

further by Krasnoperov et al. ${ }^{30}$ They noted that the latter integral of eq 6 is smaller than $Q^{\ddagger}$ because the lower limit of integration is greater than zero, and so, $k(T)$ is reduced over the value derived via eq 5 . Here, we also took into account angular momentum conservation (the $J$ quantum number) and conservation of the energy of the $\mathrm{K}$ rotor at the TS, and quantum mechanical tunneling/reflection through the barrier. The latter effect is relatively small and only increases the rate constant by $9 \%$ at $300 \mathrm{~K}, 7 \%$ at $500 \mathrm{~K}$, and $5 \%$ at $700 \mathrm{~K}$. The interaction between $\mathrm{NH}_{2}$ and $\mathrm{HCl}$ was calculated from a relaxed MPWB1K/ 


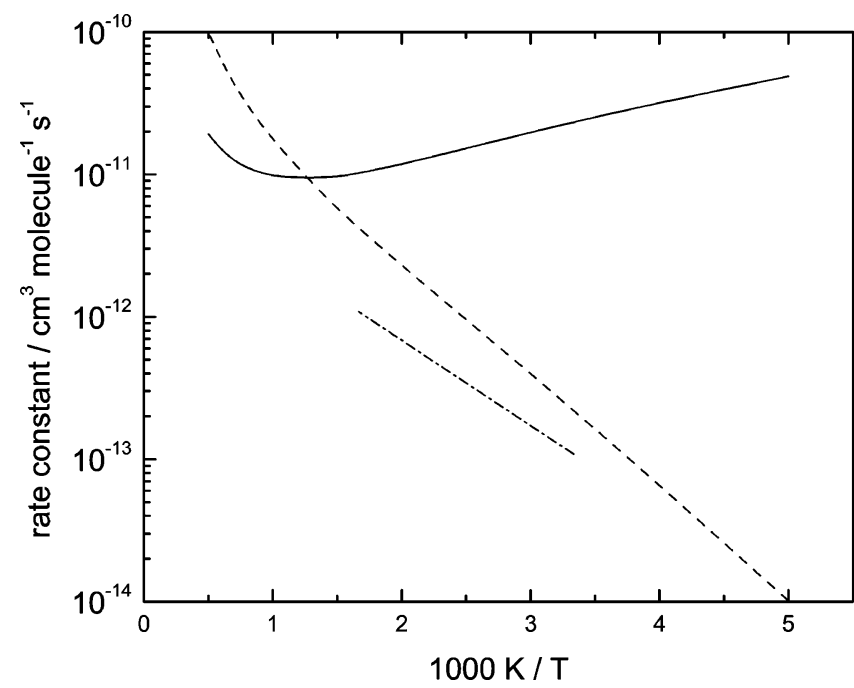

Figure 5. Comparison of theoretical and measured rate constants. Solid line, $k_{-1}(\mathrm{MTST})$ for $\mathrm{NH}_{2}+\mathrm{HCl}$; dashed line, $k_{1}(\mathrm{MTST})$ for $\mathrm{Cl}+\mathrm{NH}_{3}$; dash-dot line, experimental $k_{1}$ for $\mathrm{Cl}+\mathrm{NH}_{3}$.

$6-31++\mathrm{G}(2 \mathrm{df}, 2 \mathrm{p})$ scan. This revealed that the energy dropped rapidly enough as the separation decreased for centrifugal barriers (at relevant $J$ values) to be absent in the entrance valley leading to formation of the initial hydrogen-bonded intermediate, and thus, the reaction bottleneck is controlled by the TS. The full analytical expressions for this modified TST are given elsewhere. ${ }^{30}$

An Arrhenius plot of the computed $k_{-1}$ is shown in Figure 5. Over $250-750 \mathrm{~K}$, the theoretical rate constant is summarized by

$$
\begin{aligned}
& k_{-1}(\operatorname{MTST})= \\
& \quad 4.08 \times 10^{-13} T^{0.343} \exp (+622 / T) \mathrm{cm}^{3} \text { molecule }^{-1} \mathrm{~s}^{-1}
\end{aligned}
$$

and clearly, the predicted temperature dependence is negative below $800 \mathrm{~K}$. The deviation from the results of incorrect application of eq 5 is a factor of 3 at $298 \mathrm{~K}$ and increases with lower temperatures, so that the incorrectly derived $k_{-1}$ would be too large and the temperature dependence too negative, as discussed by Krasnoperov et al. ${ }^{30}$ There are no measurements of this $\mathrm{NH}_{2}+\mathrm{HCl}$ reaction for direct comparison with eq 7 .

Combination of $k_{-1}$ with the equilibrium constant implies

\section{$k_{1}(\operatorname{MTST})=$}

$$
1.11 \times 10^{-11} T^{0.294} \exp (-1626 / T) \mathrm{cm}^{3} \text { molecule } \mathrm{s}^{-1} \mathrm{~s}^{-1}
$$

for $\mathrm{Cl}+\mathrm{NH}_{3}$ over $250-750 \mathrm{~K}$. The agreement between $k_{1}$ (MTST) and experiment is quite good, as seen in Figure 5, considering the exponential dependence on computed barrier height. The theoretically derived rate constant is around a factor of 3 too large. This might reflect an error in the barrier of a few kilojoules per mole, or the computed TS may be too tight. Nevertheless, the approximate magnitude and temperature dependence of $k_{1}$ are rationalized in terms of a TS whose energy lies below that of the final products (Figure 4). The role of hydrogen bonding between the products is to stabilize the TS, and details of the subsequent bound complex do not enter into the analysis.

\section{Conclusions}

The measured rate constant $k_{1}$ for $\mathrm{Cl}+\mathrm{NH}_{3} \rightarrow \mathrm{NH}_{2}+\mathrm{HCl}$ exhibits an activation energy more than $7 \mathrm{~kJ} \mathrm{~mol}^{-1}$ below the endothermicity. The reaction is therefore a clear counterexample to the common assumption that, for an endothermic process, $E_{\mathrm{a}} \geq \Delta H^{\circ}$. This result can be rationalized in terms of a PES based on density functional theory, where for the reverse process there is a bound complex in the entrance channel, followed by a transition state lying below the energy of $\mathrm{NH}_{2}+\mathrm{HCl}$. Modified transition-state theory yields a negative temperature dependence for the $\mathrm{NH}_{2}+\mathrm{HCl}$ reaction and, through microscopic reversibility, fair accord with $k_{1}$.

Acknowledgment. The UNT work was supported by the Robert A. Welch Foundation (grant B-1174), the National Science Foundation (grant CTS-0113605), and the UNT Faculty Research Fund. B.P.M. was supported through UNT's NSF Research Experience for Undergraduates program (grant CHE0243795), and computer facilities were purchased with funding from the NSF (grant CHE-0342824).

\section{References and Notes}

(1) Daniels, F.; Alberty, R. A. Physical Chemistry, 2nd ed.; John Wiley: New York, 1961.

(2) Laidler, K. J.; Meiser, J. H. Physical Chemistry; Benjamin/ Cummings: Menlo Park, CA, 1982.

(3) Fontijn, A.; Zellner, R. Influence of Temperature on Rate Coefficients of Bimolecular Reactions. In Reactions of Small Transient Species; Fontijn, A., Clyne, M. A. A., Eds.; Academic: New York, 1983.

(4) Russell, J. J.; Seetula, J. A.; Gutman, D. J. Am. Chem. Soc. 1988, $110,3092$.

(5) Kalinovski, I. J.; Gutman, D.; Krasnoperov, L. N.; Goumri, A.; Yuan, W.-J.; Marshall, P. J. Phys. Chem. 1994, 98, 9551.

(6) Nicovich, J. M.; Van Dijk, C. A.; Kreutter, K. D.; Wine, P. H. J. Phys. Chem. 1991, 95, 9890.

(7) Golden, D. M. J. Phys. Chem. 1979, 83, 108.

(8) Mozurkewich, M.; Benson, S. W. J. Phys. Chem. 1984, 88, 6429.

(9) McEwen, A. B.; Golden, D. M. J. Mol. Struct. 1990, 224, 357.

(10) Benson, S. W. The Foundations of Chemical Kinetics; McGrawHill: New York, 1960.

(11) Shi, Y.; Marshall, P. J. Phys. Chem. 1991, 95, 1654.

(12) Ding, L.; Marshall, P. J. Phys. Chem. 1992, 96, 2197.

(13) Okabe, H. Photochemistry of Small Molecules; Wiley: New York, 1978.

(14) Hanf, A.; Läuter, A.; Volpp, H.-R. Chem. Phys. Lett. 2003, 368, 445 .

(15) Westenberg, A. A.; deHaas, N. J. Chem. Phys. 1977, 67, 2388.

(16) Mordaunt, D. H.; Dixon, R. N.; Ashfold, M. N. R. J. Chem. Phys. 1996, 104, 6472 .

(17) Thermodynamic Properties of Individual Substances, 4th ed.; Gurvich, L. V., Veyts, I. V., Alcock, C. B., Eds.; Hemisphere: New York, 1989; Vol. 1.

(18) Bryukov, M. G.; Slagle, I. R.; Knyazev, V. D. J. Phys. Chem. A 2002, 106, 10532 .

(19) Thermodynamic Properties of Individual Substances, 4th ed; Gurvich, L. V.; Veyts, I. V.; Alcock, C. B., Eds.; Hemisphere: New York, 1992; Vol. 2.

(20) Litorja, M.; Ruscic, B. J. Chem. Phys. 1997, 107, 9852.

(21) Corchado, J. C.; Truhlar, D. G.; Espinosa-Garcia, J. J. Chem. Phys. 2000, $112,9375$.

(22) Russell, J. J.; Seetula, J. A.; Senkan, S. M.; Gutman, D. Int. J. Chem. Kinet. 1988, 20, 759.

(23) Frisch, M. J.; Trucks, G. W.; Schlegel, H. B.; Scuseria, G. E.; Robb, M. A.; Cheeseman, J. R.; Montgomery, J. A., Jr.; Vreven, T.; Kudin, K. N.; Burant, J. C.; Millam, J. M.; Iyengar, S. S.; Tomasi, J.; Barone, V.; Mennucci, B.; Cossi, M.; Scalmani, G.; Rega, N.; Petersson, G. A.; Nakatsuji, H.; Hada, M.; Ehara, M.; Toyota, K.; Fukuda, R.; Hasegawa, J.; Ishida, M.; Nakajima, T.; Honda, Y.; Kitao, O.; Nakai, H.; Klene, M.; Li, X.; Knox, J. E.; Hratchian, H. P.; Cross, J. B.; Bakken, V.; Adamo, C.; Jaramillo, J.; Gomperts, R.; Stratmann, R. E.; Yazyev, O.; Austin, A. J.; Cammi, R.; Pomelli, C.; Ochterski, J. W.; Ayala, P. Y.; Morokuma, K.; Voth, G. A.; Salvador, P.; Dannenberg, J. J.; Zakrzewski, V. G.; Dapprich, S.; Daniels, A. D.; Strain, M. C.; Farkas, O.; Malick, D. K.; Rabuck, A. D.; Raghavachari, K.; Foresman, J. B.; Ortiz, J. V.; Cui, Q.; Baboul, A. G.; Clifford, S.; Cioslowski, J.; Stefanov, B. B.; Liu, G.; Liashenko, A.; Piskorz, P.; Komaromi, I.; Martin, R. L.; Fox, D. J.; Keith, T.; Al-Laham, 
M. A.; Peng, C. Y.; Nanayakkara, A.; Challacombe, M.; Gill, P. M. W.; Johnson, B.; Chen, W.; Wong, M. W.; Gonzalez, C.; Pople, J. A. Gaussian 03, revision C.02; Gaussian, Inc.: Wallingford, CT, 2004

(24) Baboul, A. G.; Curtiss, L. A.; Redfern, P. C.; Raghavachari, K. J. Chem. Phys. 1999, 110, 7650.

(25) Montgomery, J. A., Jr.; Frisch, M. J.; Ochterski, J. W.; Petersson, G. A. J. Chem. Phys. 1999, 110, 2822

(26) Zhao, Y.; Truhlar, D. G. J. Phys. Chem. A 2004, 108, 6908.
(27) McKee, M. L.; Nicolaides, A.; Radom, L. J. Am. Chem. Soc. 1996, $118,8,10571$.

(28) Truhlar, D. G.; Garrett, B. C.; Klippenstein, S. J. J. Phys. Chem. 1996, 100, 12771 .

(29) Garrett, B. C.; Truhlar, D. G.; Grev, R. S.; Magnuson, A. W. J. Phys. Chem. 1980, 84, 1730.

(30) Krasnoperov, L. N.; Peng, J.; Marshall, P. J. Phys. Chem. A 2006 $110,3110$. 